Ueberhaupt soll die Einwirkung des Nitromethans auf Alkohole studirt werden, und ich hoffe, bald Näheres darüber berichten zu können.

Im Anschluss an diese Versuche möchte ich noch kurz das Verhalten von Nitromethan zu Phenylhydrazin erwähnen.

Phenylhydrazin löst sich leicht in Nitromethan und krystallisirt daraus, selbst bei einer Temperatur von $20^{\circ}$, in schönen gelben Tafeln. Salzsaures Phenylhydrazin wurde mit Natriumnitromethan zu gleichen Theilen gemengt. Nach Zusatz von Wasser erfolgte eine heftige Explosion, welche das Gefäss vollständig zerschmetterte. Nitromethan wurde sodann mit Phenylhydrazin in einer Röhre zehn Stunden lang bis auf $140^{\circ}$ erhitzt. Beim Oeffnen der Röhre entwich reichlich Methylamin, welches durch die reducirende Wirkung des Phenylhydrazins aus Nitromethan gebildet ist. Die Flüssigkeit in der Röhre färbte sich roth. Nach längerem Stehen schieden sich Krystalle ab, welche wegen ihrer geringen Menge noch nicht näher untersucht werden konnten.

Leipzig, Chemisches Laboratorium, August 1885.

\title{
Notiz über Phenylparamid; von
}

B. Hötte.

Auf Anregung des Herrn Prof. E. von Meyer habe ich Versuche über das Verhalten substituirter Ammoniake gegen Mellithsäure in der Hitze angestellt. Zunächst wurde 1 Mol. Mellithsäure mit 6 Mol. Anilin im Rohre auf $160^{\circ}$ während der Dauer von 6-7 Stunden erhitzt. Als Produkt erhielt ich eine weisse, amorphe Masse, welche bei längerem. Stehen an der Iuft eine schwach grünliche Färbung annahm. Dieser Körper verhält sich den meisten Lösungsmitteln gegenüber indifferent, nur von concentrirter Schwefelsäure wird er unter starker Bräunung aufgenommen, während er durch Kochen damit Zersetzung erleidet. Die Analyse dieser Substanz, welche bei $300^{\circ}$ noch nicht schmilzt, zeigte, dass sich hei obigem Processe Phenylparamid, $\mathrm{C}_{30} \mathrm{H}_{15} \mathrm{O}_{8} \mathrm{~N}_{3}=$ $\mathrm{C}_{6}\left(\mathrm{CO} / \mathrm{NC}_{6} \mathrm{H}_{5}\right)_{3}$ gebildet habe.

0,3001 Grm. gaben 0,7702 Grm. $\mathrm{CO}_{2}$ und 0,0846 Grm. $\mathrm{H}_{2} \mathrm{O}$.

0,2438, gaben bei $22^{\circ}$ und $757 \mathrm{Mm}$. Bar. $18,1 \mathrm{Ccm}$. N.

Hieraus ergeben sich folgende Procentzahlen: 


$\begin{array}{ccc} & \text { Berechnet. } & \text { Gefunden. } \\ \mathrm{C} & 70,17 & 69,86 \\ \mathrm{H} & \mathbf{2}, 90 & 3,13 \\ \mathrm{~N} & 8,23 & 8,37\end{array}$

Gleichzeitig habe ich auf anderem Wege das Phenylparamid dargestellt. Mellithsaures Ammon wurde mit überschüssigem Anilin auf $170^{\circ}$ zwei Tage lang erhitzt, wobei viel Ammoniak entwich. Der auf diesem Wege aus beiden Agentien erhaltene Körper zeigte, nachdem er einige Male mit Alkohol aufgekocht war, genau dasselbe Verhalten, wie das vorhin beschriebene Phenylparamid. Eine Stickstoffbestimmung desselben bestätigte diese Vermuthung.

0,2637 Grm. gaben bei $21^{\circ}$ und $760 \mathrm{Mm}$. Bar. 19,4 Cem. N, was folgender Procentzahl entspricht:

$$
\begin{array}{ccc} 
& \text { Berechuet. } & \text { Gefunden. } \\
\mathrm{N} & 8,23 & 8,37
\end{array}
$$

Der Bildungsprocess des Phenylparamids aus Mellithsäure und Anilin kann durch folgende Gleichungen versinnlicht werden:

$$
\begin{aligned}
& \mathrm{C}_{6}(\mathrm{COOH})_{6}+6 \mathrm{C}_{6} \mathrm{H}_{5} \mathrm{H}_{2} \mathrm{~N}=\mathrm{C}_{6}\left(\mathrm{COC}_{6} \mathrm{H}_{5} \mathrm{HN}\right)_{6}+6 \mathrm{H}_{2} \mathrm{O} \text {. } \\
& \mathrm{C}_{6}\left(\mathrm{COCO}_{6} \mathrm{H}_{5} \mathrm{HN}\right)_{6}=\mathrm{C}_{6}\left(\underset{\mathrm{CO}}{\mathrm{CO}} \int_{6} \mathrm{C}_{6} \mathrm{H}_{5} \mathrm{~N}\right)_{3}+3 \mathrm{C}_{6} \mathrm{H}_{7} \mathrm{~N} \text {. }
\end{aligned}
$$

Ich wollte auch das dem Phenylparamid entsprechende Methylparamid darstellen, indem ich eine wässrige, 30 proc. Methylaminlösung auf Mellithsäure in derselben Weise, wie schon erläutert, einwirken liess. Als Produkt dieser Einwirkung erhielt ich einen weissen, in Wasser leicht löslichen Körper. Beim Uebergiessen desselben mit Kalilauge liess ein sofortiges Auftreten von Methylamin darauf schliessen, dass nur saures mellithsaures Methylamin gebildet sei.

Zugleich möge hier erwähnt werden, dass ich augenblicklich die Einwirkung von Phenylhydrazin auf melrbasische organische Säuren und deren Anhydride studire. So sei hier bemerkt, dass durch Wechselwirkung gleicher Moleküle Phenylhydrazin und Phtalsäureanhydrid unter Abspaltung von Wasser ein in schönen gelben Nadeln krystallisirender Körper entsteht, dessen Schmelzpunkt bei $175^{\circ}$ bis $176^{\circ}$ liegt. - Ich hoffe bald ausführlicher darüber berichten zu können.

Leipzig, Chemisches Laboratorium, August 1885. 